the cork is turned again and the bottle made impervious. Heating for an hour in all has generally been employed. Malt extract may be mixed with milk and the whole sterilized. Milk may be sterilized in bulk in tin trays or bottles by means of steam, in Koch's sterilizer. If possible, not more than an hour should elapse between milking and sterilization of the milk. Hay bacteria are not always destroyed by sterilization, but the bacteria producing acids are destroyed. The practical value of sterilization is proven.

G Y NEOOLOY.

UNDER THE CHARGE OF

HENRY C. COE, M.D., M.R.C.S., OF NEW YORK.

Observations on the Origin of Ovarian Cysts.

Heneage Gibbes (Boston Medical and Surgical Journal, January 30, 1890) discusses tliree causes of cystic disease of the ovarics, viz.: 1. Overgrowth of preëxisting tissue; 2. Degenerative changes, giving rise to cavities or cysts; 3. Simple distention of Graafian vesicles. The first mode of formation is by the overgrowth of epithelial cells, which arc probably of embryonjc origin. Cysts thus derived have a wall lined with these polyhedral, granular cells, which are frequently vacuọlated. The cavity contains a coagulated material, which is structureless and gives a different reaction from either colloid matter or liquor folliculi. A comparison is instituted between these groups of cells and the condition described by Dr. Mary A. Dixon Jones as "endothelioma," the writer believing that they are identical and that there is no reason to believe that it resembles carcimona, either in its structure or in its progress.

The formation of cysts by degenerative processes is usually described as due to a colloid transformation of the stroma, but the homogeneous hyaline material into which the tissue is changed does not give the colloid reaction.

The third mode of origin is by the dilatation of ovisac, the wall of the cyst being constituted by the condensed stroma. The microscope throws no light upon the causa ultina.

\title{
STERILITY IN WOMAN.
}

OLIVer (Liverpool Medico Chirurgical Journal, January, 1890) contributes a sensible article on this subject, in which lie takes the position that there is too much unnecessary treatment of the female for the cure of sterility which is really due to the male. Gynecologists are too apt to infer that because a woman has been married for years, without impedinent to the sexual act, and has never become pregnant, therefore there is some anatomical defect in her pelvic organs. "A semblance of brilliant results obtained by a too meddle. some interference may be paraded, but careful observation teaches us that the good which follows is invariably the outcome of an enforced sexual rest." There are many occult causes of unfruitfulness with which we are unacquainted, even whell there are no apparent obstacles to conception. The 
writer estimates that one woman out of every fifteen is sterile, hence the male percentagc is mucl higher-one in six, according to Gross.

[We cannot sufficiently commend a writer who calls attention forcibly to the injustice which is done to unfruitful women not only by their husbands, but too often by gynecologists. There are many able specialists who, whellever they find a slight anteflexion associated with sterility, at once jump at the conclusion that the latter is directly dependent upon the former, that it is unnecessary to seek further for a cause of the sterility, and that the only treatment is-divulsion and the introduction of a stem. This is all the more remarkable, because those same men would never think of making such a hasty deduction under any other circumstances. Statistics of numerous miraculous cures of sterility by any given method of overcoming a supposed cervical stenosis are not useful to the general profession if they lead them to make extravagant promises to their patients, which are only followed by bitter disappointment.-E. $\dot{\boldsymbol{D}}$.]

\section{The Results of the Removal of Diseased Ovaries and Tubes.}

IMLACH (Ibid.) has taken the precaution to obtain the after-history of many of his patients (of whom he has operated upon 142), in order to ascertain their subsequent conditiou. In forty-three cascs of oöphoritis and salpingitis eighty per cent. were much improved in health and were free from pain, but menstruation (metrostaxis?) had entirely ceased in only sixty per cent. Eleven womeu from whom cystic ovaries had been removed were all in perfect health. Thirty-four patients who had been operated upon for ovarian abscess or pyosalpinx were greatly benefited, but twenty-five per cent. still complained of pain, and in forty per cent. menstruation was still regular. Of eighteen women who had hydrosalpiux, fourteen were cured, and four were in poor healtll.

Out of thirty-six cases of removal of the adnexa for the relief of hemorrhage from uterine fibroids, menstruation ceased in between sixty-five aud seventy per cent. within a period of six months, and in the other cases it recurred normally. In only one instance did profuse hemorrhage continue. "In all cases in which pain was severe or disabling, it has been relieved." In some instances the writer believes that the diseased condition of the appendages (and they are, he says, invariably diseased) causes the rapid enlargement of the tumor, which quickly diminishes in size as soon as the stimulus to growth is removed. The removal of healthy ovaries and tubes in the case of large uterine tuniors is of doubtful benefit; if any surgical interference is indicated, hysterectomy is preferable.

\section{Myomotomy and Splenotomy in the game Patient.}

Bollicr (Raccoglitore med.; Centralblatt für Gynäkologie, October 26, 1889) reports the case of a woman, aged thirty-eight, upon whom he performed laparotomy for the relief of uterine hemorrhages due to the presence of a fibro-myoma in the anterior uterine wall. Nearly all of the uterus was removed with the tumor, the stump being treated according to the intraperitoneal metlod. A wandering spleen, weighing seven and one-half ounces, was removed at the same time, the patient making a good recovery. 